\title{
The Role of Saline Infusion Sonohysterography in the Evalution of the Uterus of Infertile Patients
}

\author{
Önder Aydın³, Serkan Kumbasar², Süleyman Salmann', Hale Akınn ${ }^{4}$ Ayşenur Kumbasar ${ }^{5}$, Erman Sever ${ }^{2}$ \\ ${ }^{1}$ Clinic of Obstetrics and Gynecology, Gaziosmanpaşa Taksim Training and Research Hospital, İstanbul, Turkey \\ ${ }^{2}$ Clinic of Obstetrics and Gynecology, Sakarya Training and Research Hospital, Sakarya, Turkey \\ ${ }^{3}$ Clinic of Obstetrics and Gynecology, Bağcılar Traning and Research Hospital, İstanbul, Turkey \\ ${ }^{4}$ Clinic of Obstetrics and Gynecology,Süleymaniye Obstetrics and Pediatrics Training and Research Hospital, İstanbul, Turkey \\ ${ }^{5} \mathrm{Clinic}$ of Anesthesiology and Reanimation, Sakarya Training and Research Hospital, Sakarya, Turkey
}

\section{ABSTRACT}

Objective: Evaluation of the uterus is one of the indispensable components of routine infertility examinations. The aim of this study is to evaluate the utility of endometrial screening with contrast media during the assessment of the uterus with transvaginal ultrasonography (TvUSG) in infertility researches.

Methods: One hundred and two infertile patients who were referred to Süleymaniye Obstetrics and Gynecology Hospital because of infertility underwent saline infusion sonohysterography (SIS) at our clinic. The cases were informed about the procedure, and consent forms were obtained. Data was collected prospectively. Results were compared with a large patient cohort that was evaluated with only hysterography (HSG) and TvUSG for uterus assessment.

Results: Abnormal intracavitary findings were observed in $20.5 \%$ of the 102 infertile patients who had undergone SIS. This rate was $7.4 \%$ in the control group. Total abnormal intracavitary finding rate of the SIS group was significantly higher $(p<0.01)$. The rates of the uterine anomalies were similar in two groups; $4.9 \%$ in the SIS group and $5.03 \%$ in the control group. There was no statistically significant difference between the uterine anomaly rates of the groups $(p>0.05)$.

Conclusion: SIS is a practical, low-cost method that does not require specific equipment; in addition to these advantages, it is effective in the detection of intrauterine pathologies and for making differential diagnosis. In consideration of the higher frequency of uterine pathologies in infertile patients, SIS can be used as a routine test in infertility researches. (JAREM 2015; 5: 102-6)

Keywords: Infertility, hysterosalpingography, sonohysterography, hysteroscopy, transvaginal ultrasonography

\section{INTRODUCTION}

Evaluating the uterus is an inseparable part of routine infertility research. During the evaluation of the uterus through transvaginal ultrasound (TVUSG), endometrial imaging using contrast media has been used in clinical practice. This method is less invasive and cheaper than hysterosalpingography (HSG) and hysteroscopy $(\mathrm{H} / \mathrm{S})$. Saline infusion sonohysterography (SIS) comprises transcervical infusion of a sterile saline solution to the endometrial lumen during TvUSG. Saline expands the uterine cavity and forms a perfect contrast in defining the echogenic endometrium because it is anechoic. This technique was first described 27 years ago (1). Its high sensitivity and efficiency in detecting endometrial polyps, submucosal fibroids (myoma), synechiae, and uterine abnormalities have been proved in some studies $(2,3)$. In recent meta-analysis, SIS was compared with hysterectomy, $\mathrm{H} / \mathrm{S}$, and histological sampling, which are the gold standard diagnostic methods. It was found that SIS is easily applicable and has high accuracy in diagnosing abnormal uterine bleeding (4). In addition, SIS is less invasive and less expensive than HSG and H/S. In this study, we evaluated the uterus through SIS as part of routine infertility research. We planned a prospective study for this purpose. We investigated whether SIS could be used as a part of infertility research.

\section{METHODS}

Saline infusion sonohysterography was performed in 102 infertile women in our center for infertility research. Patients were informed about the procedure, and their written informed consent was obtained. After SIS, they were referred to the relevant departments for additional diagnostic and therapeutic procedures (laparoscopy or H/S) when required. Data were prospectively collected. The results that we obtained were compared with a large patient cohort where only HSG and TVUSG were used for uterine evaluation.

Women with regular menstrual cycles were examined in the follicular phase of their cycles. First, two-dimensional TvUSG was routinely performed. Then, SIS was performed. A $5-\mathrm{MHz}$ frequency vaginal probe (Toshiba justvision 400, Tokyo, Japan) was used in both procedures. The cervix was reached with a standard bivalve disposable vaginal speculum. The cervix was wiped with povidone-iodine. Then, an 8-F balloon-tipped catheter was driven up to the back of the os through the cervical canal and placed. The balloon was inflated with $1 \mathrm{cc}$ of saline. Then, the catheter was brought into the proper position by gentle pulling. After removing the speculum, the vaginal probe was placed again. The endometrial lumen was expanded by slowly injecting $20-50 \mathrm{~mL}$ of saline along with TVUSG. Images were taken in the midsagittal section. At the end of the process, the balloon was emptied 
and the catheter was pulled out. Analgesics, antibiotics, or sedatives were not used before or after the operation. The diagnoses made by SIS were divided into two and recorded as uterine cavity pathologies or uterine anomalies.

\section{Uterine cavity pathologies:}

- Normal uterine cavity; smooth endometrium and normal regular contours.

- Endometrial polyp; hyperechogenic peduncle lesion.

- Submucosal fibroids; mixed echogenic lesion disrupting endometrial continuity.

- Intrauterine adhesions; asymmetric dense echogenic lesion and hypoechoic cystic areas in the cavity.

- Intramural fibroids; well-circumscribed intramural lesion.

\section{Uterine anomalies:}

- Arcuate uterus; greater than $0.1 \mathrm{~cm}$ fundal indentation of the cavity between the two horns.

- Uterus bicornis.

- Uterus unicornis.

- Uterine septum.

- Uterus didelphys.

\section{Statistical Analysis}

When evaluating the results obtained in this study, statistical softwares NCSS 2007 and PASS 2008 (Utah, USA) were used for statistical analysis. While the data were evaluated, the Student's t-test was used for comparison of the quantitative data in addition to descriptive statistical methods (mean, standard deviation, and frequency). The chi-square test and Fisher's exact test were used in the comparison of qualitative data. Results were evaluated at the $95 \%$ confidence interval, and significance was set at $\mathrm{p}<0.05$.

\section{RESULTS}

Saline infusion sonohysterography was performed in a total of 102 patients (9.7\%) whose ages ranged from 18 to 41 . The mean age of the patients was $30.15 \pm 5.57$. SIS was not performed in 954 patients (90.3\%); thus, they were designated as the control group. The average age of the control group was 31.49 \pm 5.64 . The duration of infertility of the patients in whom SIS was performed ranged from 1 to 20 years and the average infertility duration was $8.99 \pm 5.03$ years. The infertility duration in the control group ranged from 1 to 24 years, and the average infertility duration was $7.11 \pm 5.04$ years. While the infertility type in $74.9 \%$ of the patients was primary, it was secondary in $25.1 \%$ (Table 1).

The average age of the patients in whom SIS was performed was statistically significantly lower than the mean age of the patients in the control group. Infertility duration of the patients who underwent SIS was statistically significantly higher than the than of the patients in the control group $(p<0.01)$. No statistically significant difference was found between the distribution of infertility types between the two groups ( $p>0.05)$.

Saline infusion sonohysterography was successfully performed in a total of 102 patients. No difficulties or complications were encountered during or after the operation. While the result of
SIS was normal in $70.6 \%$ of the 102 patients who underwent SIS, polyps were observed in $13.7 \%$, uterus arcuatus in $5.9 \%$, submucosal myoma in $3.9 \%$, uterine septum in $2.9 \%$, endometrial polyps+uterus arcuatus in $2 \%$, and uterine synechiae in 1 patient (Table 2). More intracavitary abnormalities were observed in the SIS group than in the control group (Table 3).

Endometrial polyps were found in $15.6 \%$ of the 102 infertile patients who underwent SIS. This rate is $1.3 \%$ in the control group. The rate of polypendometrial diagnosis in the SIS group was detected to be statistically significantly higher $(p<0.01)$. Submucosal myoma was seen in $3.9 \%$ of the 102 infertile patients who underwent SIS; this rate was $5.34 \%$ in the control group, and no statistically significant difference was seen between the rates of submucosal fibroids ( $p>0.05$ ). Adhesion was seen in $0.9 \%$ of the 102 infertile patients who underwent SIS; this rate is $0.73 \%$ in the control group, and no statistically significant difference was seen between the rates of adhesion ( $p>0.05)$. Abnormal intracavitary findings were found in $20.5 \%$ of the 102 infertile patients who underwent SIS; this was $7.4 \%$ in the control group. The total proportion of abnormal intracavitary findings was found to be significantly higher in the SIS group $(p<0.01)$.

Uterine anomalies were similar to each other in both groups (Table 4). While $5.03 \%$ in the SIS group, they were $4.9 \%$ in the control group. No statistically significant difference was seen between the rates of uterine abnormalities in the groups $(p>0.05)$. The most frequent uterine anomaly detected in both groups was an arcuate uterus. The second most frequent uterine anomaly detected in both groups was a septate uterus. No known complications developed during and after the application of sonohysterography.

\section{DISCUSSION}

Saline infusion sonohysterography is an easy, safe, and well tolerated alternative when compared with diagnostic $\mathrm{H} / \mathrm{S}$ because it offers comprehensive and unique advantages in imaging the uterus and adnexa. In addition, the endometrial imaging is better. Intrauterine pathologies and uterine anomalies are also better evaluated (3). The diagnostic accuracy of SIS in abnormal uterine bleeding was found equal with diagnostic $\mathrm{H} / \mathrm{S}$ in a recently conducted meta-analysis conducted with 2278 people. It has $95 \%$ of

\section{Table 1. The assessment of defining features according to the groups}

\begin{tabular}{|c|c|c|c|}
\hline & $\begin{array}{l}\text { SIS group } \\
(n=102) \\
\text { Mean } \pm \text { SD }\end{array}$ & $\begin{array}{l}\text { Control group } \\
(n=954) \\
\text { Mean } \pm \text { SD }\end{array}$ & •p \\
\hline Age & $30.15 \pm 5.57$ & $31.49 \pm 5.64$ & $0.023^{*}$ \\
\hline Infertility duration & $8.99 \pm 5.03$ & $7.11 \pm 5.04$ & $0.001 * *$ \\
\hline Type of infertility & n (\%) & n (\%) & $+p$ \\
\hline Primary & $73(71.6)$ & 717 (75.2) & \multirow{2}{*}{0.417} \\
\hline Secondary & $29(28.4)$ & $236(24.8)$ & \\
\hline \multicolumn{4}{|c|}{$\begin{array}{l}\text { SD: standard deviation; n: number; SIS: saline infusion sonohysterography; } \\
\text {-Student's t-test was used; * } p<0.05 \\
{ }^{+} \text {Chi-square test was used; }{ }^{* \star} p<0.01\end{array}$} \\
\hline
\end{tabular}




\section{Table 2. Distribution of SIS results}

\begin{tabular}{|l|c|c|}
\hline & $\mathbf{n}$ & \% \\
\hline Polyp & 14 & 13.7 \\
\hline Submucosal myoma & 4 & 3.9 \\
\hline Arcuate & 6 & 5.9 \\
\hline Septum & 3 & 2.9 \\
\hline Polyps+Arcuate & 2 & 2.0 \\
\hline Synechiae & 1 & 1 \\
\hline Normal & 72 & 70.6 \\
\hline SIS: saline infusion sonohysterography & & \\
\hline
\end{tabular}

Table 3. The prevalence of intracavitary abnormalities detected with SIS

\begin{tabular}{l|c|c|c|}
\hline $\begin{array}{l}\text { Diagnoses of } \\
\text { uterine cavity }\end{array}$ & $\begin{array}{c}\text { SIS group } \\
(\mathbf{n = 1 0 2 )}\end{array}$ & $\begin{array}{c}\text { Control group } \\
(\mathbf{n = 9 5 4 )}\end{array}$ & ·p \\
\hline Endometrial polyp & $16(15.6 \%)$ & $13(1.36 \%)$ & $0.001^{\star \star}$ \\
\hline Submucosal myoma & $4(3.9 \%)$ & $51(5.34 \%)$ & 0.538 \\
\hline Adhesion & $1(0.9 \%)$ & $7(0.73 \%)$ & 0.785 \\
\hline $\begin{array}{l}\text { Total intracavitary } \\
\text { abnormalities }\end{array}$ & $21(20.5 \%)$ & $71(7.4 \%)$ & $0.001^{\star \star}$ \\
\hline $\begin{array}{l}\text { SIS: saline infusion sonohysterography } \\
\text { •: Chi-square test } \\
\text { ** } p<0.01\end{array}$ & & \\
\hline
\end{tabular}

Table 4. The prevalence of uterine anomalies detected with SIS

\begin{tabular}{|l|c|c|c|}
\hline $\begin{array}{l}\text { Uterine } \\
\text { abnormalities }\end{array}$ & $\begin{array}{c}\text { SIS group } \\
(\mathbf{n = 1 0 2 )}\end{array}$ & $\begin{array}{c}\text { Control group } \\
(\mathbf{n = 9 5 4 )}\end{array}$ & ; \\
\hline Arcuate uterus & $3(2.9 \%)$ & $27(2.83 \%)$ & 0.949 \\
\hline Septate uterus & $2(1.9 \%)$ & $19(1.99 \%)$ & 0.983 \\
\hline Unicornuate uterus & $0(0.0 \%)$ & $1(0.10 \%)$ & $\dagger 1.000$ \\
\hline Bicornuate uterus & $0(0.0 \%)$ & $1(0.10 \%)$ & $\dagger 1.000$ \\
\hline Total uterine anomalies & $5(4.9 \%)$ & $48(5.03 \%)$ & 0.95 \\
\hline $\begin{array}{l}\text { SIS: saline infusion sonohysterography } \\
\text { •: Chi-square test } \\
\text { †: Fisher's exact test }\end{array}$ & & \\
\hline
\end{tabular}

the sensitivity and $88 \%$ of the specificity (4). The diagnostic accuracy of SIS was investigated in infertile patients and similar results were found $(2,5,6)$. In this study, we used SIS for uterine imaging and investigated whether or not SIS could be a routine part of infertility examinations. In order to evaluate the uterus, routine SIS was performed in 102 patients admitted to our hospital with the complaint of infertility. Intracavitary abnormalities were detected in $20.5 \%$ of these patients (polyps, submucosal fibroids, adhesions, etc.). The results we found were similar to other studies in which SIS was performed for infertility research (5-7).
Kim et al. (6) performed routine SIS in 72 diseased patients before the IVF and detected intracavitary abnormalities at a rate of $11.1 \%$. They also reported that the main pathology found was polyps. Lindheim and Sauer (7) performed SIS in 50 patients waiting for oocyte donation and determined uterine pathologies in $38 \%$ of them (polyps, submucosal fibroids, adhesions, and a bicornuate uterus).

The most detected pathology in our study was also polyps and fibroids, and this is consistent with other studies. de Kron et al. (4) detected intracavitary abnormalities in $56 \%$ of 877 patients who they gathered in a meta-analysis study. Endometrial polyp was the most frequently encountered intracavitary lesion in infertile patients.

The data supporting a polypectomy before infertility treatment are increasing. In a prospective randomized study conducted with 415 IVF patients, it was concluded that polypectomy was effective and increased pregnancy rates compared to the control group (8). In another study of 215 infertile patients where polypectomy was performed before intrauterine insemination, it was concluded that polypectomy increased the pregnancy rate 2.1 times (9). Studies have shown that polypectomy restores the reproductive capacity (10). Submucosal fibroids are the second most common lesion among intracavitary lesions in the patient group of SIS. There are several studies reporting that submucosal fibroids reduce the success of assisted reproductive treatment (11). Large fibroids have an adverse effect on fertility by disrupting the cavity. Indeed, increasing pregnancy rates compared to the control group after myomectomy support this claim. In this regard, the adverse effects of submucosal fibroids and polyps that distort the cavity on implantation can easily be understood.

In our study, the rate of uterine abnormalities was $4.9 \%$ in the infertile patient group of SIS. This rate was $5.03 \%$ in the control group and the rate of uterine anomaly was similar in both groups. In the literature, uterine anomaly rates in infertile patients range from $1 \%$ to $26 \%$. This wide range of prevalence can be attributed to several limiting factors among studies. These reasons include population, diagnostic methods, classification systems, and the excluding of asymptomatic cases. The most common uterine anomaly found in our study was arcuate uterine in the infertile group of SIS. $2.9 \%$ of the SIS group and $60 \%$ of the anomalies were arcuate uterine. A septate uterus was the second most frequently found. In total, $1.9 \%$ of patients and $40 \%$ of the anomalies were a partial or complete septate uterus. Two studies in the literature have reported that the ratio of a septate uterus in the anomalies was $22 \%$ and $34.9 \%(12,13)$. These rates are lower than those in our study. However, in these two studies, the ratio of an arcuate uterus in abnormalities was reported as 15\% and 18.3\% $(12,13)$. These are quite low rates when compared to the rate of $60 \%$ in our study. The reason for this may be that they considered a moderate arcuate uterus as a variant of normal. The relationship of an arcuate uterus with infertility is uncertain. It is usually interpreted that an arcuate uterus has no effect on fertility. Grimbizis et al. (13) concluded that an arcuate uterus reduced reproductive performance, but it was the anomaly that affects reproductive performance the least.

Uterine cavity appears as a line in two-dimensional TVUSG. However, both the uterine cavity and myometrium can be displayed 
simultaneously with the help of SIS. When the patients were evaluated with SIS, they are not exposed to radiation as in HSG. When compared with TVUSG and HSG, the two most commonly used techniques in uterine evaluation, SIS was reported in several studies to have many advantages.

Soares et al. (14) accepted H/S as the gold standard and investigated the diagnostic accuracy of SIS by comparing it with TVUSG and HSG. SIS has similar diagnostic accuracy rates with H/S for endometrial polyps and endometrial hyperplasia. However, the sensitivity of TVUSG for these two lesions was $75 \%$. The sensitivity of HSG is $50 \%$ for endometrial polyps and $0 \%$ for endometrial hyperplasia. The sensitivity of SIS and HSG is similar only in intrauterine adhesions, and it is $75 \%$. However, the sensitivity of TVUSG for adhesions is $0 \%$. In another comparative study, $\mathrm{H} / \mathrm{S}$ was taken as the gold standard and SIS was compared with TvUSG. Ragni et al. (3) included 98 infertile patients in this study. They found in this study that SIS had a higher diagnostic accuracy rate than TVUSG in intrauterine pathologies. When compared with $\mathrm{H} / \mathrm{S}$, the sensitivity of SIS was found to be $98 \%$ and the specificity was $95 \%$; whereas the sensitivity of TVUSG was found to be $91 \%$ and the specificity was $83 \%$. Considering all these, we can conclude that SIS is more advantageous than TVUSG and HSG.

SIS was shown to be more preeminent than TVUSG and HSG in the diagnosis of uterine malformations. Soares et al. (14) reported that the sensitivity of SIS was higher than that of TVUSG and HSG. The sensitivity of TVUSG and HSG is $44.5 \%$ and that of SIS is $77.8 \%$. Alborzi et al. (15) examined 20 patients with recurrent pregnancy loss and an HSG diagnosis of a septate/bicornuate uterus. They reached the conclusion that SIS makes a better distinction of a septate/bicornuate uterus than HSG. The authors suggest that the distinction of a septate/bicornuate uterus can be made without laparoscopy in SIS.

Saline infusion sonohysterography can be easily used even in stimulated cycles because it does not disrupt the characteristics of the endometrium. The authors claim that the application of this method would be more appropriate especially in infertility cases before applying invasive and expensive hysteroscopic examinations and report that the sensitivity of SIS is $87.5 \%$, specificity is $100 \%$, positive predictive value is $100 \%$, and negative predictive value is $91.6 \%$ in detecting any anomalies in the cavity. In assisted reproduction centers, SIS was reported to be more preeminent than TVUSG in determining submucosal cores of fibroids in a uterus with multiple fibroids cores. It is also a method that can easily differentiate a hyperplastic endometrium from a large polyp. In addition, the differential diagnosis of an arcuate uterus and uterine septum can be made easily and accurately with this method (16).

The predictivity of SIS was found to be $90 \%$ in infertility centers and was reported to have a higher rate of sensitivity and predictive values, as in HSG, in the detection of pathologies of the endometrial cavity. In the same study, the preeminence of SIS was emphasized in terms of better imaging of intrauterine pathology (17).

In addition to advantages such as easy implementation, low processing costs, and not requiring special equipment, SIS gives valuable results in the detection and differential diagnosis of intrauterine pathologies in particular. In the literature, the sensitiv- ity and specificity of sonohysterography for intrauterine lesions vary from approximately $75 \%$ to $100 \%$ and specificity is higher than sensitivity at a rate of $2-20 \%$ in all studies. Sonohysterography is considered as the gold standard in intrauterine lesions, particularly in the detection of polyps and submucosal fibroids. In many studies, it is even recommended in $\mathrm{H} / \mathrm{S}$ contraindications to reduce the cost of patient management.

Saline infusion sonohysterography increased the sensitivity of ultrasonography in intrauterine lesions from $62.5 \%$ to $96.9 \%$ $(p=0.0006)$, specificity from $97.5 \%$ to $100 \%(p=0.1587)$, positive predictive value from $95.2 \%$ to $100 \%(p=0.1902)$, negative predictive value from $76.5 \%$ to $97.6 \%$ ( $p=0.0024)$, and the total value of diagnostic accuracy from $81.9 \%$ to $98.6 \%(p=0.0003)$.

Therefore, in cases where we are unsure of the diagnostic value and strength of ultrasonography or want to increase its strength, we should apply SIS.

\section{CONCLUSION}

Saline infusion sonohysterography can be used for the recognition of uterine pathologies of infertile patients because it is a safe, cheap, and well-tolerated technique. Moreover, it can be easily applied by many infertility clinics giving outpatient service because the hospitalization of patients is not required. Considering the high frequency of uterine pathologies in infertile patients, SIS should be used routinely in infertility research.

Ethics Committee Approval: Ethics committee approval was not required when the study was made.

Informed Consent: Written informed consent was obtained from patients who participated in this study.

Peer-review: Externally peer-reviewed.

Author Contributions: Concept - Ö.A., S.K.; Design - Ö.A., H.A., S.K.; Supervision - Ö.A., S.K., H.A.; Resources - Ö.A., S.S., H.A., E.S., A.K.; Materials - A.K., E.S.; Data Collection and/or Processing - Ö.A., S.K., E.S.; Analysis and/or Interpretation - Ö.A., S.S., E.S.; Writing Manuscript - Ö.A., S.K., S.S.; Critical Review - S.S., A.K., H.A.

Conflict of Interest: No conflict of interest was declared by the authors.

Financial Disclosure: The authors declared that this study has received no financial support.

\section{REFERENCES}

1. Ricman TS, Viscomi GN, deCherney A, Polan ML, Alcebo LO. Fallopian tubal patency assessed by ultrasound following fluid injection. Radiology 1984: 152: 507-10. [CrossRef]

2. Parsons AK, Lense JJ. Sonohysterography for endometrial abnormalites;preliminary results. J Clin Ultrasound 1993; 21: 87-95. [CrossRef]

3. Ragni G, Diaferia D, Vegetti W, Colombo M, Arnoldi M, Crosignani PG. Effectivness of sonography in infertil patient work-up: a comparision with transvaginal ultrasonography and hysteroscopy. Gynecol Obstet Invest 2005; 59: 184-8. [CrossRef]

4. de Kron CD, de Bock GH, Dieben SW, Jansen FW. Saline contrast hysterosonography in abnormal uterine bleeding: a systematic review and meta-analysis. BJOG 2003; 110: 938-47. [CrossRef]

5. Valenzano MM, Mistrangelo E, Lijioi D, Fortunato T, Lantieri PB, Risso D, et al. Transvaginal sonohysterographic evaluation of uterine malformations. Eur J Obstet Gynecol Reprod Biol 2006; 124: 246-9. [CrossRef] 
6. Kim AH, McKay H, Keltz MD, Nelson HP, Adamson GD. Sonohysterographic screening before in vitro fertilization. Fertil Steril 1998; 69: 841-4. [CrossRef]

7. Lindheim SR, Sauer MV. Upper genital tractscreening with hysterosonography in patients with abnormal uterine bleeding. Ultrasound Obsted Gynecol 2001; 18: 54-61.

8. Demirol A, Gurgan T. Effect of treatment of intrauterine pathologies with Office hysteroscopy in patients with recurrent IVF failure. Reprod Biomed Online 2004; 8: 590-4. [CrossRef]

9. Pérez-Medina T, Bajo-Arenas J, Salazar F, Redondo T, Sanfrutos L, Alvarez $\mathrm{P}$, et al. Endometrial polyps and their implication in the pregnancy rates of patients undergoing intrauterin insemination: a prospective, randomizet study. Hum Reprod 2005; 10: 767-9.

10. Preutthipan S, Herabutya Y. Hysteroscopic polipectomy in 240 premenopausal and postmenopausal women. Fertil Steril 2005; 83: 7059. [CrossRef]

11. Stovall DW, Parrish SB, Van Voorish BJ, Hahn SJ, Sparks AE, Syroup $\mathrm{CH}$. Uterine leiyomyomas reduce the efficacy of assisted reproduction cycles: results of a matched followup study. Hum Reprod 1998; 13: 192-7. [CrossRef]
12. Acien P. Incidence of Mullerian defects in fertil and infertile women. Hum Reprod Update 2001; 7: 161-74.

13. Grimbizis GF, Camus M, Tarlatzis BC, Bontis JN, Devroey P. Clinical implications of uterin malformations and hysteroscopic treatment results. Hum Reprod Update 2001; 7: 161-74. [CrossRef]

14. Soares SR, Barbosa dos Reis MM, Camargos AF. Diagnostic accuracy of sonohysterography, transvaginal sonography and hysterosalpingography in patients with uterine cavity diseases. Fertil Steril 2000; 73: 406-11. [CrossRef]

15. Alborzi S, Dehbashi S, Parsanezhad ME. Diferential diagnosis of septate and bicorniate uterus by sonohysterography eliminates the need for laparoscopy. Fertil Steril 2002; 78: 176-8. [CrossRef]

16. Ayida G, Chamberlain P, Barlow D, Kennedy S. Uterine cavity assessment prior to in vitro fertilization: comparison of transvaginal scanning, saline contrast hysterosonography and hysteroscopy. Ultrasound Obstet Gynecol 1997; 10: 59-62. [CrossRef]

17. Lindenheim SR, Sauer MV. Upper genital tract screening with hysterosonography in patients receving donated oocytes. Int J Gynaecol Obstet 1998; 60: 47-50. [CrossRef] 